\title{
Elements of Gameful Design Emerging from User Preferences
}

\author{
Gustavo F. Tondello \\ HCI Games Group \\ Games Institute \\ University of Waterloo \\ gustavo@tondello.com
}

\author{
Alberto Mora \\ Estudis d'Informàtica, \\ Multimedia i Telecomunicació \\ Universitat Oberta de Catalunya \\ amoraca@uoc.edu
}

\author{
Lennart E. Nacke \\ HCI Games Group \\ Games Institute \\ University of Waterloo \\ lennart.nacke@acm.org
}

\begin{abstract}
Several studies have developed models to explain player preferences. These models have been developed for digital games; however, they have been frequently applied in gameful design (i.e., designing non-game applications with game elements) without empirical validation of their fit to this different context. It is not clear if users experience game elements embedded in applications similarly to how players experience them in games. Consequently, we still lack a conceptual framework of design elements built specifically for a gamification context. To fill this gap, we propose a classification of eight groups of gameful design elements produced from an exploratory factor analysis based on participants' self-reported preferences. We describe the characteristics of the users who are more likely to enjoy each group of design elements in terms of their gender, age, gamification user type, and personality traits. Our main contribution is providing an overview of which design elements work best for what demographic clusters and how we can apply this knowledge to design effective gameful systems.
\end{abstract}

\section{ACM Classification Keywords}

H.1.2. User/Machine Systems: Human Factors; K.8.0 Personal Computing: Games.

\section{Author Keywords}

Gamification; Gameful Design; Games User Research; User Types; Game Design Elements

\section{INTRODUCTION}

Research on gameplay motivations has shown that players have diverse personal preferences regarding how and what they play $[20,33,44]$. Researchers have developed player type models [20, 27] or gamer motivation scales [43, 44] to capture the diverse styles of play exhibited by different players. This information has been increasingly used in gamification-using game design elements in non-game contexts [14]- to model user behaviour and design more engaging gameful systems.

\footnotetext{
Permission to make digital or hard copies of all or part of this work for personal or classroom use is granted without fee provided that copies are not made or distributed for profit or commercial advantage and that copies bear this notice and the full citation on the first page. Copyrights for components of this work owned by others than the author(s) must be honored. Abstracting with credit is permitted. To copy otherwise, or republish, to post on servers or to redistribute to lists, requires prior specific permission and/or a fee. Request permissions from permissions@acm.org.

CHI PLAY '17, October 15-18, 2017, Amsterdam, Netherlands

(C) 2017 Copyright held by the owner/author(s). Publication rights licensed to ACM. ISBN 978-1-4503-4898-0/17/10 . .\$15.00
}

DOI: https : //doi .org/10.1145/3116595. 3116627
Gameful systems are effective when they help users achieve their goals. This often involves educating users about topics in which they lack knowledge, supporting them in attitude or behaviour change, or engaging them in specific areas [10]. To make gameful systems more effective, several researchers have attempted to model user preferences in these systems, such as user typologies [40], persuasive strategies [31], or preferences for different game elements based on personality traits [21]. Nevertheless, none of these models have studied elements used specifically in gameful design. To select design elements that can appeal to different motivations, designers still rely on player typologies_-such as Bartle's player types [3, 4] or the BrainHex player types [27]—or classifications of game elements - such as the gamer motivation profile [43].

However, the applicability of these models in gamification has not been supported by empirical evidence as of yet. All of them were developed by asking participants about their experiences when playing games. Hence, they cannot be transferred one-by-one to gameful applications. Tondello et al. [40] have studied correlations between several design elements used in gameful design with the HEXAD user types. However, they have not proposed a classification of gameful design elements. Thus, we still lack a conceptual framework of design elements commonly used in gamification. The purpose of the current study was to fill this gap. Therefore, we propose a new conceptual framework for classifying gameful design elements based on participants' self-reported preferences to understand user behaviour in gamification. While the HEXAD framework [40] describes psychological characteristics of the users, this work proposes a novel way to organize gameful design elements.

To operationalise the proposed framework, we asked participants about how much they enjoy 59 design elements frequently used in gameful systems (gathered from a literature review). Next, we conducted an exploratory factor analysis to cluster these design elements into eight groups. We adopt a conceptual definition of element similar to that employed by Deterding et al. [14]. Thus, we consider that 'gameful design elements' are the building blocks that are characteristic to gameful systems - meaning elements that are found in many (but not necessarily all) gameful systems - and play a significant role in the emerging user experience with the system. Additionally, Deterding and colleagues suggest that gamification and gameful design are coincident concepts, framing the same extension of the phenomena through different inten- 
tions. Hence, these gameful design elements could be applied interchangeably in both gamification and gameful design.

Moreover, after establishing a model of gameful design elements, we further analyzed the data to find patterns that could potentially be used to inform gameful design. Therefore, we also present results that depict the overall participant's preferences for each group of design elements, as well as the relationship between the design element groups with the HEXAD user types, personality traits, age, and gender.

This contribution is important to human-computer interaction (HCI) and gamification because it presents the first conceptual framework of design elements constructed in the specific context of gameful design and based on user preferences. Gamification researchers and practitioners have relied - until now-on models that were previously created in the context of games, assuming that they would be generalizable to gamification without empirical evidence. Our work enables future studies and industry applications to be built upon a model empirically constructed and validated specially for gamification.

Furthermore, current gameful design practice often involves selecting design elements from a list to try and recreate patterns found in games, with little guidance regarding how each design element affects the user experience [13, 25, 28]. Design elements are usually classified by their motivational significance or structural characteristics [13], but these classifications do not help designers choose the best pattern to solve specific user needs. As a result, designers often rely on some combination of a small subset of design elements, such as points, badges, and leaderboards, simply because these are the easiest elements to implement. Therefore, a better understanding of the effects of each design element is needed to foster the utilization of a broader variety of elements selected to solve specific needs. Our work contributes with the fulfillment of this need by presenting a novel classification of gameful design elements based on user preferences, thus allowing designers to better understand the potential effect of each element on user enjoyment and make more informed design decisions.

\section{RELATED WORK}

Researchers in HCI and games have been studying different motivations and playing styles for over a decade and representing them in player typologies. Hamari and Tuunanen [20] conducted a systematic review of these models to investigate their commonalities. The authors note that massively multiplayer online (MMOs) and other types of online games are more frequently covered than other genres. This compromises the generalizability and applicability of these models. Furthermore, they compared all the analyzed models and suggested that they could be synthesized in five key dimensions: achievement, exploration, sociability, domination, and immersion.

One of the oldest player type models is Bartle's player types [3]. He studied what players desired from multi-user dungeons (MUDs) based on a discussion between dozens of senior players and identified four player types on two axes that express the player's desire to interact with or act on the virtual world or other players: achievers (acting on the world), explorers (interacting with the world), socialisers (interacting with other players), and killers (acting on other players). Bartle later extended the model by adding a third dimension [4]: implicit or explicit (i.e., whether the player actions are automatic and unconscious or considered and planned). Bartle's model is frequently used by gamification practitioners because of its simplicity. However, it was never empirically validated nor was it intended to be used outside of the domain of MUDs.

Based on a factor analysis of questions inspired by the original Bartle's player types, Yee [42, 44] identified three main components of player motivation with ten sub-components: achievement (advancement, mechanics, competition), social (socializing, relationship, teamwork), and immersion (discovery, roleplaying, customization, escapism). More recently, Yee [43] expanded on his previous work by conducting a factor analysis with over 140,000 participants and developed a 'gamer motivation profile' composed of 12 dimensions grouped in 6 clusters: action (destruction and excitement), social (competition and community), mastery (challenge and strategy), achievement (competition and power), immersion (fantasy and story), and creativity (design and discovery). This recent proprietary investigation intended to capture player motivations towards many different games and was empirically supported by factor analysis. However, a standard assessment tool is not publicly and readily available.

With a different approach, the first 'demographic game design' model (DGD1) [7] tried to include a wider perspective regarding player types by adapting the Myers-Briggs type indicator (MBTI) [26] to games. The second 'demographic game design' model (DGD2) [5] explored the hardcore to casual dimension, different skill sets, and the preference for single and multiplayer gameplay. These two models served as a base on which the BrainHex player typology was built. BrainHex [5, 27] is a top-down player typology, which takes inspiration from neurobiological player satisfaction research [6], previous typology approaches, discussions of patterns of play, and the literature on game emotions to build seven archetypes denoting distinct experiences of play. The seven BrainHex archetypes (and their associated player motivations) are: achiever (completion), conqueror (challenge), daredevil (excitement and risk), mastermind (strategic reasoning), seeker (exploration and curiosity), socialiser (social interactions), and survival (frightening experiences). BrainHex supplements existing research with a diverse array of player types. However, initial empirical investigation on its psychometric properties has shown low reliability scores [9].

While these models are often used for personalizing gameful systems, they were built for games. However, in gameful design, only elements of games are included in non-game applications. Therefore, there is no evidence of the generalizability of game motivation models to gameful design because users might experience game elements embedded into applications differently than how they are experienced in games. Consequently, recent works have proposed new models specifically built to explain user preferences in gameful systems.

In the context of gamification, Marczewski [22] built on the literature about player types and self-determination theory in games $[38,39]$ to create the user types HEXAD model, which 
classifies distinct user preferences. The six HEXAD user types (and the motivation they represent) are: philanthropist (altruism), socialiser (relatedness), free spirit (autonomy), achiever (competence), player (rewards), and disruptor (change).

Additionally, Ferro et al. [17] studied personality models and player types. The goals were to find the similarities between them and to relate them to different game design elements. Their work grouped personality traits, player types, and game elements into five categories: dominant, objectivist, humanist, inquisitive, and creative. Jia et al. [21] studied the relation between the five-factor model (FFM) personality traits [19] and individual gamification elements and found several significant correlations. Orji et al. [31] studied the relation between the FFM personality traits and several persuasive strategies used in gamification and found significant correlations. Barata et al. $[1,2]$ studied data regarding student performance and gaming preferences from a gamified university-level course and identified different patterns in student behaviour, which the authors suggested could be used in future gamified education projects to tailor the course to different students.

Although these models provide useful insights about user experience with gameful systems, they do not provide detailed information about user's preference for different gameful design elements. In this regard, Tondello et al. [40] tested the correlation of each HEXAD user type with 32 game elements commonly used in gamification. Their results provide a starting point to understand the user's relation with gameful design elements. However, they did not develop a model to cluster different design elements together, nor studied how different factors (such as gender, age, or personality) affect user's preferences for different design elements. Therefore, the present study will advance the extant literature on this topic by proposing a framework of gameful design elements and studying which factors influence users' preferences towards them.

With a different approach, some authors have proposed taxonomies or classifications of gameful design elements based on other specific criteria. Phillips et al. [34] suggested a taxonomy of videogame rewards based on prior literature and focus group studies. Rapp [36] also discussed the classification of videogame rewards, based on an ethnographic study of World of Warcraft [8], and discussed potential applications of his model to gameful design. While both these models provide valuable information that can inform the design of rewards systems in gamification, they are limited to a specific design element, whereas our work is broad and encompasses dozens of design elements (including rewards), without diving into details regarding any of them. Differently, Exton and Murray [16] suggested a taxonomy of gameful design elements based on a theoretical evaluation of their motivational properties. Each element was classified according to their envisioned potential to afford either type of motivation descried by self-determination theory [38]: competence, autonomy, or relatedness. Robinson and Bellotti [37] proposed a preliminary taxonomy of gamification elements based on how much anticipated commitment was expected from the user. However, none of these taxonomies consider different user preferences as we do in our contribution.
It is also noteworthy that despite the existing literature on user preferences in gamification and games, most gameful design methods do not take user preference in consideration as part of their process $[24,25]$. One explanation for the lack of consideration for user preferences in design methods might be the difficulty of translating the existing models directly into design guidance. Nonetheless, several studies have shown that user preferences can significantly affect the effectiveness of instrumental game systems (e.g., [10, 30, 31, 32]); therefore, we can expect that this will also happen in gameful systems. Our work will contribute to the improvement of design methods by providing a classification of gameful design elements that will help designers better understand user preferences and translate this information into design guidance.

\section{METHODOLOGY}

The process of creating a framework of gameful design elements followed these steps:

1. Survey design: a literature review to create a list of gameful design elements commonly employed in gamification;

2. Data collection: an online survey to understand participants' preferences for the elements in the list;

3. Factor analysis: a principal component analysis to cluster the elements into groups according to user preferences;

4. Component interpretation: an analysis of the composition of each cluster to interpret and label them;

5. Hierarchical clustering: a hierarchical cluster analysis to further cluster the element groups into high level constructs.

\section{Survey Design}

We compiled a list of gameful design elements for the survey by conducting an informal literature review of both academic and non-academic sources. By also reviewing non-academic sources, we purposefully included design elements that are frequently used by practitioners, but have not been examined in HCI studies yet. Thus, we provide the first study of how these elements relate to other elements that have already been investigated and how they explain user preferences.

The final list contains 59 gameful design elements. Academic sources included Tondello et al. [40] (56\%), Jia et al. [21] (14\%), and Ferro et al. [17] (19\%). The inclusion criterion was peer-reviewed publications that contained a list of design elements used in the specific context of gamification, thus excluding publications in the context of gaming. Non-academic sources included lists of gamification elements from the following resources: Gamified UK [23] (73\%), Yu-kai Chou Gamification [12] (34\%), Enterprise Gamification [15] (29\%), Werbach and Hunter [41] (27\%), and Zichermann and Cunningham [45] (24\%). The inclusion criteria were publications that contained a list of design elements used in the specific context of gamification and were published by authors who have been consistently listed in one of the top 100 positions in Rise's Gamification Gurus Power 100 board ${ }^{1}$. The numbers in brackets refer to the percentage of the 59 surveyed elements that were identified in each source; they add up over $100 \%$ because many elements appeared in more than one source.

\footnotetext{
${ }^{1}$ https://www.rise.global/gurus
} 
The process of creating the list of design elements consisted on reviewing the selected sources one by one and adding all the elements described in the source with enough details to understand how they are applied. Additionally, before being added to the list, each new element was compared with the elements already in the list for similarities in their name or description. Elements that were considered similar in the researchers' judgment were merged together, whereas each different element was added as a new entry. We have provided the complete list in the appendix. It includes information about the source for each element and their descriptions as presented in the survey.

\section{Survey Instrument}

The survey was deployed as an online instrument between February and March 2017 using the LimeSurvey software. All questions were in English and were grouped as follows:

User types: The 24-items HEXAD user types scale [40].

Preferred gameful design elements: We asked how much participants enjoyed the 59 different design elements commonly used in gamification on a 5-point Likert scale.

Personality: The 10-items Big 5 [19] personality traits scale (BFI-10) [35].

Demographic information: Participant's country, language, age, gender, education, and gaming habits and preferences.

The survey could be completed anonymously and, prior to the decision to participate, participants were presented with an online informed consent form. In addition, the long question groups (user types and gameful design elements) had attention check questions (e.g., "Please select ' 3 ' in this item to show us that you are carefully reading all questions.") to verify if participants were reading all the items with attention.

\section{Participants}

We recruited participants by email (in both academic and nonacademic environments), social networks (Facebook, Twitter, and Reddit), and online gaming forums. Participants were required to be at least 15 years old to participate and were not offered a direct remuneration, but they were offered an opportunity to enter a draw to win one of two $\$ 50$ prizes.

In total, 196 participants completed the survey. However, we discarded eight participants who did not complete all question groups or failed to select the correct answer in at least one of the attention check items. Therefore, the final dataset contained 188 responses (124 men, 53 women, 4 transgender, 3 non-binary, and 4 did not indicate their gender). Participants' age ranged from 15 to $71(M=26.7, S D=9.7)$ and were skewed towards younger participants (with $74 \%$ of participants being 30 or less), possibly because of the topic of the survey being more appealing to a younger audience. Participants were distributed geographically as follows: $60.6 \%$ from North America, 25.5\% from Europe, 5.3\% from South America, $4.8 \%$ from Oceania, 2.7\% from Asia, and 1.1\% from Africa. However, $98.9 \%$ of participants reported having a very good or native understanding of English. Therefore, we operate under the assumption that lack of English proficiency was not a detriment to our study.
Participants' scores in the HEXAD user types followed a similar distribution as previous reports [23, 40], with the following means and standard deviations: Free Spirit: 23.1 (2.8); Philanthropist: 22.8 (3.6); Achiever: 22.4 (3.4); Player: 21.1 (4.0); Socialiser: 18.3 (4.8); and Disruptor: 15.4 (4.6).

\section{RESULTS}

In this section, we first present the exploratory factor analysis used to cluster the gameful design elements into eight groups. Next, we describe the characteristics of each group and their average scores in the participant sample. Finally, we analyze how the independent variables (user type scores, personality traits, gender, and age) influence the element groups' scores. All analyses were conducted in SPSS 23 (IBM, 2015).

\section{Exploratory Factor Analysis}

We employed a principal component analysis (PCA) to cluster the 59 surveyed gameful design elements into groups. PCA is a standard method for creating groupings in data based on the covariance and correlation of items. This allowed us to establish a classification and analyze user preferences with a more manageable number of categories.

Since our investigation was exploratory, the first step was to evaluate if all the included gameful design elements could be successfully grouped into clusters because we had no prior theory to justify the inclusion or exclusion of each element. A PCA requires variables to be at least partially correlated between themselves to be able to reduce the number of components. Thus, we first analyzed the correlation matrix between all 59 variables and removed variables with only three or less relevant correlations. We considered correlations with $r>=.3$ as relevant, as suggested by Field [18] (p. 648). Moreover, we also performed an initial PCA and noted the variables that appeared isolated in one of the components-meaning variables that were the only item loading highly in one of the components-and removed them. We performed this procedure three times, until we found no more variables to remove.

After the removal process, we had removed a total of ten variables from the analysis (16.9\%): Non-linear gameplay, Anonymity, Anarchic gameplay, Tutorials, Loss aversion, Time pressure, Scarcity, Aura effect, Protection, and Virtual worlds. This means that these variables could not be clustered with any other of the variables in the dataset.

For the final dataset with the remaining 49 variables, the Kaiser-Meyer-Olkin measure verified the sample adequacy for the analysis, $K M O=.77$ (a good sample size, according to Field [18]). Moreover, Bartlett's test of sphericity was significant $\left(\chi_{1176}^{2}=3486.2, p<.001\right)$, indicating that the correlations between items were sufficiently large for PCA.

We used parallel analysis and Velicer's minimum average partial (MAP) test to determine the number of components to retain in the final analysis because these procedures are validated and, hence, more adequate than a simple eigenvalues inspection [29]. The analyses suggested we should retain eight components. Moreover, we used an Oblimin rotation because we expected that some elements could appear in more than one component. Table 1 presents the final structure matrix. 


\begin{tabular}{|c|c|c|c|c|c|c|c|c|}
\hline \multirow[b]{2}{*}{ Gameful design elements } & \multicolumn{8}{|c|}{ Components } \\
\hline & $\mathbf{1}$ & 2 & 3 & 4 & 5 & 6 & 7 & 8 \\
\hline Social comparison or pressure & .821 & & & & & & & \\
\hline Leaderboards & .801 & & & & & & & \\
\hline Social competition & .789 & & & & & & & \\
\hline Social networks & .720 & & & & & & & \\
\hline Social status & .716 & & & & & & & \\
\hline Guilds or teams & .668 & & & & & & -.430 & \\
\hline Friend invite & .647 & & & & & & -.420 & \\
\hline Social discovery & 617 & & & & & & -.419 & \\
\hline Trading & .536 & & & & & & -.388 & \\
\hline Scarlet letter & .527 & .377 & & & & & -.414 & -.381 \\
\hline Glowing choice & & .819 & & & & & & \\
\hline Beginner's luck & & .695 & & & & & & \\
\hline Signposting & & .626 & & & & & & \\
\hline Anchor juxtaposition & & .561 & & & & & & \\
\hline Power-ups or boosters & & .555 & & & & & & \\
\hline Humanity hero & & .516 & .371 & & & -.395 & -.363 & \\
\hline Personalization & & .511 & & & -.427 & & & \\
\hline Free lunch & & .488 & & & & & & -.390 \\
\hline Mystery box & & & .700 & & & & & \\
\hline Easter eggs & & & .673 & & & & & \\
\hline Theme & & & .625 & & & & & \\
\hline Narrative or story & & & .485 & & & & & -.361 \\
\hline Access & & & & .632 & & & & \\
\hline Lotteries or games of chance & & & & .580 & & & & \\
\hline Boss battles & .371 & & & .547 & & & & \\
\hline Challenges & & & .401 & .490 & & & & \\
\hline Avatar & & & & & -.761 & & & \\
\hline Customization & & & & & -.761 & & & \\
\hline Points & & & & .361 & -.604 & & & -.352 \\
\hline Virtual economy & & & & .376 & -.446 & & & \\
\hline Levels or progression & & & & & & -.620 & & \\
\hline Meaning or purpose & & & & & & -.584 & & \\
\hline Progress feedback & & & & & & -.539 & & -.358 \\
\hline Learning & & & .404 & & & -.459 & & \\
\hline Knowledge sharing & & & & & & & -.680 & \\
\hline Gifting & .475 & & & & & & -.657 & \\
\hline Innovation platforms & & & & & & & -.651 & \\
\hline Development tools & & & & & & & -.625 & \\
\hline Administrative roles & & & & & & & -.568 & \\
\hline Voting mechanisms & & & & & & & -.496 & \\
\hline Exploratory tasks & & & .457 & & & & -.487 & \\
\hline Creativity tools & & & & & -.399 & & -.456 & \\
\hline Meaningful choices & & & & & & -.391 & -.448 & \\
\hline Badges or achievements & & & & & & & & -.830 \\
\hline Certificates & & & & & & & & -.736 \\
\hline Collection & & & & & & & & -.594 \\
\hline Rewards or prizes & & & & .389 & -.381 & & & -.530 \\
\hline Unlockable or rare content & & & .436 & & & & & -.506 \\
\hline Quests & & & & & -.366 & -.438 & & -.494 \\
\hline Internal reliability $(\alpha)$ & .874 & .787 & .736 & .668 & .696 & .674 & .844 & .771 \\
\hline Eigenvalues & 9.077 & 4.164 & 3.123 & 2.577 & 2.154 & 1.855 & 1.769 & 1.694 \\
\hline$\%$ of variance & 18.524 & 8.498 & 6.374 & 5.260 & 4.397 & 3.785 & 3.610 & 3.457 \\
\hline
\end{tabular}

Notes. Extraction method: Principal component analysis. Rotation method: Oblimin with Kaiser normalization.

The components were labelled: (1) socialization, (2) assistance, (3) immersion, (4) risk/reward, (5) customization, (6) progression, (7) altruism, (8) incentive. For improved visualization, the factor loadings $<.36$ (absolute values) are suppressed.

Table 1. Exploratory factor analysis (structure matrix) of the gameful design elements. 
Field [18] (p. 644) recommends considering factor loadings greater than .36 as significant for a sample size of 200 and an alpha level of .01. Thus, we calculated the scores and internal reliability coefficients for each component using all the gameful design elements that loaded higher than .36 in the component. All components showed adequate reliability with $\alpha>=.674$ (see Table 1).

\section{Component Interpretation}

After completing the PCA, we analyzed the composition of each component to interpret and label them. First, two researchers interpreted the component structure matrix independently. Next, both compared their interpretations, discussed similarities and divergences, and agreed on a label for each component. We labelled the eight components as follows:

1: Socialization. All elements in this component correspond to some form of social interaction, including both collaborative, competitive, and entirely social interactions.

2: Assistance. All elements in this component correspond to the user receiving some sort of aid for their progression, either from the system or from other users.

3: Immersion. The highest loading elements in this component are related to immersion and curiosity. This component includes elements related with a narrative or story and elements related with exploration and unpredictability.

4: Risk/Reward. The highest loading elements in this component are related to challenges, gambling, and the rewards that come from winning. Thus, this component represents the expectation of winning economically or socially valuable prizes both from challenges and lotteries.

5: Customization. The highest loading elements in this component are related to three different ways of customizing one's own experience: (1) customizing the user's avatar or experience, (2) automatic personalization, or (3) redeeming freely chosen goods with virtual currency or points.

6: Progression. The elements in this component are related to progression and meaning. Thus, this component represents the will to be involved in meaningful goals and to feel one is progressing towards achieving them.

7: Altruism. All elements in this component correspond to diverse ways of making a useful contribution, either to the system or to other users, including sharing knowledge or goods, contributing to improve the system, and collaborating with other users.

8: Incentive. All elements in this component correspond to incentives or rewards that the user might receive, such as badges, achievements, collectible items, and rewards.

Table 2 presents the descriptive statistics for the eight groups of gameful design elements. We calculated the mean and standard deviation based of the original 5-point Likert scale responses to all the items that loaded higher than .36 in each component. Overall, immersion and progression are the groups of design elements that score higher in user preferences, whereas socialization and assistance are the groups that score lower. However, the difference is not extensive: there is only a 1.15point difference out of $5.0(23 \%)$ in the difference between the highest and the lowest scoring groups.

For greater precision in the correlation analyses, we also computed participants' standardized scores for each one of the eight components as part of the PCA using the regression method. Standardizing the linear regression model generates scores for each component with a mean of zero and a standard deviation of 1.0. We used the scores calculated with this method for all subsequent correlation analyses.

Table 2 also shows the bivariate correlations of the eight groups between themselves. There is a moderate correlation between socialization and altruism, which is explained by the fact that both are related to social interactions. The difference is that the focus of the former is on the interactions themselves, whereas the latter is more focused on making a contribution, which can be directed at other users, but also at the system. There are also significant, but weaker correlations between socialization and incentive; assistance and customization; assistance and incentive; immersion and altruism; customization and incentive; and altruism and incentive. It is noteworthy that incentive showed the highest number of correlations (four).

\section{Factors that Influence User Preferences}

To understand which factors influence user preferences for each one of the eight gameful design element groups, we analyzed how the participant's user type scores, personality traits, age, and gender influenced their scores for each group.

\begin{tabular}{l|cc|cccccccr} 
& \multicolumn{10}{|c|}{ Correlations $(r)$} \\
Components & Mean & SD & $\mathbf{1}$ & $\mathbf{2}$ & $\mathbf{3}$ & $\mathbf{4}$ & $\mathbf{5}$ & $\mathbf{6}$ & $\mathbf{7}$ & $\mathbf{8}$ \\
\hline 1- Socialization & 3.15 & 0.71 & - & & & & & & \\
2- Assistance & 3.02 & 0.68 & .042 & - & & & & & \\
3- Immersion & 4.17 & 0.46 & .065 & .008 & - & & & & \\
4- Risk/Reward & 3.60 & 0.56 & .143 & .029 & .003 & - & & & \\
5- Customization & 3.92 & 0.53 & .069 & $.157^{*}$ & .078 & .055 & - & & \\
6- Progression & 4.16 & 0.46 & .147 & .056 & .103 & .088 & .071 & - & \\
7- Altruism & 3.57 & 0.54 & $.281^{* *}$ & .050 & $.164^{*}$ & .033 & .150 & .101 & - \\
8- Incentive & 3.78 & 0.53 & $.157^{*}$ & .172 & .132 & .121 & $.199 *$ & .131 & $.174^{*}-$ \\
\hline$* p<.05 . \quad * * p<.01$. & & & & & & & & & \\
$*$
\end{tabular}

Table 2. Descriptive statistics for the groups of gameful design elements and bivariate correlations between them. 


\begin{tabular}{l|cccccc} 
& \multicolumn{7}{|c}{ Correlations $(r)$} & & \\
Components & Free Spirit & Philanthropist & Achiever & Player & Socialiser & Disruptor \\
\hline 1- Socialization & .003 & .104 & $.283^{* *}$ & $.263^{* *}$ & $.480^{* *}$ & .125 \\
2- Assistance & .126 & .112 & -.015 & -.016 & $.190^{*}$ & .025 \\
3- Immersion & $.406^{* *}$ & $.170^{*}$ & $.394^{* *}$ & .053 & .100 & $.165^{*}$ \\
4- Risk/Reward & .120 & .084 & $.361^{* *}$ & $.247^{* *}$ & .026 & $.183^{*}$ \\
5- Customization & .117 & -.019 & -.070 & .130 & -.069 & .006 \\
6- Progression & .013 & $.170^{*}$ & $.186^{*}$ & .104 & .072 & .084 \\
7- Altruism & .149 & $.377^{* *}$ & $.179^{*}$ & .143 & $.227^{* *}$ & .093 \\
8- Incentive & .030 & .024 & .056 & $.351^{* *}$ & .103 & .003 \\
\hline
\end{tabular}

$* p<.05 . \quad * * p<.01$.

Table 3. Bivariate correlations between the groups of gameful design elements and the HEXAD user types.

\begin{tabular}{l|ccccc} 
Components & Extraversion & Agreeableness & $\begin{array}{c}\text { Correlations }(r) \\
\text { Conscientiousness }\end{array}$ & Neuroticism & Openness \\
\hline 1- Socialization & $.323^{* *}$ & .067 & .029 & -.144 & -.027 \\
2- Assistance & $.316^{* *}$ & .106 & .040 & .046 & .147 \\
3- Immersion & .035 & .119 & .019 & .119 & .140 \\
4- Risk/Reward & .086 & -.077 & .068 & -.030 & -.019 \\
5- Customization & .035 & .000 & -.154 & .145 & $.306^{* *}$ \\
6- Progression & .031 & -.080 & .079 & .044 & -.044 \\
7- Altruism & .002 & .015 & .053 & .092 & .084 \\
8- Incentive & .107 & .052 & -.136 & $.194^{*}$ & .019 \\
\hline
\end{tabular}

$* p<.05 . \quad * * p<.01$.

Table 4. Bivariate correlations between the groups of gameful design elements and the Big 5 personality traits.

\section{User Types}

Table 3 presents the bivariate correlations coefficients between the groups of gameful design elements and participant's user type scores. The results lead to the following interpretation:

1. Socialization elements are strongly preferred by socialisers. In addition, achievers and players also show a moderate preference for these elements.

2. Assistance elements only show a weak preference by socialisers. Other than that, the user type scores do not influence the preference for receiving aid.

3. Immersion elements are strongly preferred by free spirits and achievers. Moreover, philanthropists and disruptors also show a weak preference for these elements.

4. Risk/Reward elements are moderately preferred by achievers and players and slightly preferred by disruptors.

5. Customization elements' preferences do not seem to be affected by the participant's user type scores at all.

6. Progression elements are only marginally preferred by achievers and philanthropists.

7. Altruism elements are strongly preferred by philanthropists. Additionally, there is a moderate preference by socialisers and a lighter preference by achievers.

8. Incentive elements are strongly preferred by players.

\section{Personality Traits}

Table 4 presents the bivariate correlation coefficients between the groups of gameful design elements and participant's personality traits scores. Results show that extraversion can partly explain the preferences for socialization and assistance, openness can partly explain the preference for customization, and neuroticism can partly explain the preference for incentive. However, these correlations are only moderate in strength.

\section{Age and Gender}

Table 5 presents the relationship between the groups of gameful design elements and the participant's age and gender. The results suggest that preferences for risk and reward, customization, altruism, and incentive decrease slightly with age. Socialization and immersion also seemed to slightly decrease with age, while assistance seemed to slightly increase with age, but the effects were not significant. Finally, the preference for progression was the most stable irrespective of age.

We only analyzed the data for the two main genders (female and male) because the number of participants who selfidentified with other genders was too small to allow us to conduct statistical tests. Women scored significantly higher than men in assistance, immersion, customization, and incentive. On the other hand, men scored significantly higher in socialization and altruism. These results suggest that men tend to be more sociable and collaborative in gameful systems, whereas women tend to be more immersed in the narrative, customize their experience more often, and are generally more willing to receive aid. 


\begin{tabular}{|c|c|c|c|c|c|c|c|c|c|c|c|c|}
\hline \multirow[t]{2}{*}{ Components } & \multirow[t]{2}{*}{ Age $(r)$} & \multicolumn{2}{|c|}{ Female } & \multicolumn{2}{|c|}{ Male } & \multicolumn{3}{|c|}{ T-test } & \multicolumn{2}{|c|}{ Mean Differences } & \multicolumn{2}{|c|}{$95 \% \mathrm{CI}$} \\
\hline & & $\mathbf{M}$ & SD & $\mathbf{M}$ & SD & $\mathbf{t}$ & df & $\mathbf{p}$ & $\mathbf{M}$ & SD & lower & upper \\
\hline 1- Socialization & -.138 & -0.366 & 1.027 & 0.205 & 0.941 & -3.269 & 148 & .001 & -0.571 & 0.175 & -0.915 & -0.226 \\
\hline 2- Assistance & .113 & 0.628 & 0.856 & -0.287 & 0.944 & 0.508 & 148 & .000 & 0.915 & 0.166 & 0.587 & 1.243 \\
\hline 3- Immersion & -.137 & 0.369 & 0.949 & -0.076 & 0.952 & 2.596 & 148 & .010 & 0.446 & 0.172 & 0.106 & 0.785 \\
\hline 4- Risk/Reward & $-.150 *$ & 0.020 & 0.969 & -0.016 & 0.995 & 0.201 & 148 & .841 & 0.036 & 0.178 & -0.316 & 0.388 \\
\hline 5- Customization & $-.186^{*}$ & 0.311 & 1.008 & -0.136 & 0.984 & 2.499 & 148 & .014 & 0.447 & 0.179 & 0.094 & 0.801 \\
\hline 6- Progression & -.004 & 0.165 & 1.000 & -0.073 & 1.004 & 0.312 & 148 & .192 & 0.238 & 0.181 & -0.120 & 0.595 \\
\hline 7- Altruism & $-.175^{*}$ & -0.246 & 0.922 & 0.130 & 0.977 & -2.168 & 148 & .032 & -0.376 & 0.174 & -0.719 & -0.033 \\
\hline 8- Incentive & $-.162 *$ & 0.233 & 0.965 & -0.112 & 1.002 & 1.930 & 148 & .055 & 0.346 & 0.179 & -0.008 & 0.700 \\
\hline
\end{tabular}

$* p<.05$.

Table 5. Bivariate correlations between the groups of gameful design elements and age and independent samples $T$ test between the groups and gender.

\section{Hierarchical Clustering}

To verify if the groups of gameful design elements could be further clustered into higher level categories, we performed a hierarchical cluster analysis. This is important to understand how the groups relate to each other. The results demonstrate that the eight groups of gameful design elements can be further clustered into three high-level motivational categories (see Table 6). Figure 1 shows the resulting dendrogram.

\begin{tabular}{lll} 
Categories & Groups & Notes \\
\hline $\begin{array}{l}\text { INDIVIDUAL } \\
\text { MOTIVATIONS }\end{array}$ & $\begin{array}{l}\text { 3- Immersion } \\
\text { 6- Progression }\end{array}$ & $\begin{array}{l}\text { This represents the user's } \\
\text { interest in their own } \\
\text { experience within the system. }\end{array}$ \\
\hline EXTERNAL & $\begin{array}{l}\text { 4- Risk/Reward } \\
\text { 5- Customization } \\
\text { 8- Incentive }\end{array}$ & $\begin{array}{l}\text { This represents the user's } \\
\text { interest in earning external } \\
\text { incentives and tailoring the } \\
\text { system to them. }\end{array}$ \\
\hline $\begin{array}{l}\text { SOCIAL } \\
\text { MOTIVATIONS }\end{array}$ & $\begin{array}{l}\text { 1- Socialization } \\
\text { 2- Assistance }\end{array}$ & $\begin{array}{l}\text { This represents the user's } \\
\text { interest in relatedness and } \\
\text { social interactions. }\end{array}$ \\
\hline
\end{tabular}

Table 6. High level categories of gameful design elements.

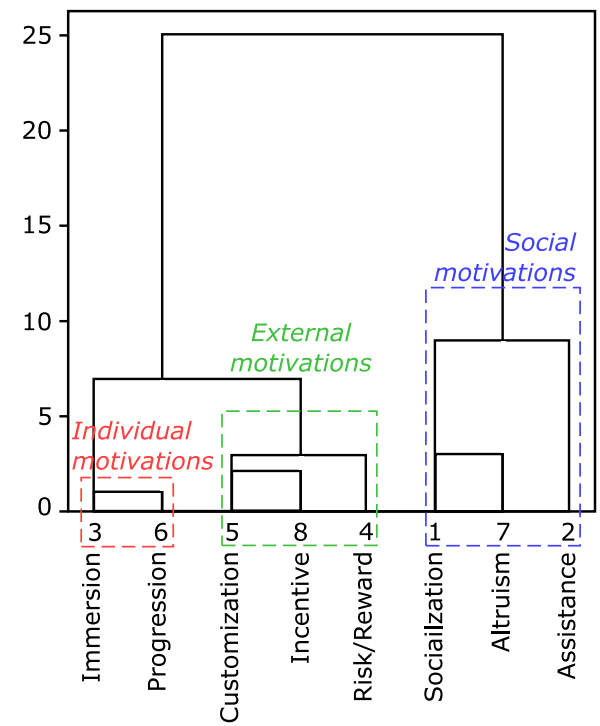

Note. Ward linkage; squared Euclidean distance. The dendrogram shows how the groups can be hierarchically clustered according to their proximity in participants' responses.

Figure 1. Dendrogram of the groups of gameful design elements.

\section{DISCUSSION}

The findings from this study show that 49 of the most frequently used gameful design elements can be grouped into eight principal components according to user preferences. In addition, we showed that 10 out of the 59 elements included in our survey could not be grouped with any other. The overall difference between the components regarding user preferences is not extraordinary but still pronounced, with approximately $20 \%$ difference between the lowest and the highest scoring groups. Moreover, by analyzing how the participants' gender, age, user types, and personality traits influenced their scores in each group, we established a clear model of user preferences:

1. Socialization elements are preferred by men, socialisers, and extroverts.

2. Assistance elements are preferred by women and extroverts.

3. Immersion elements are preferred by women, achievers, and free spirits.

4. Risk/Reward elements are preferred by younger achievers and players.

5. Customization elements are preferred by younger women who are more open to experiences.

6. Progression preferences are not clearly explained by any of studied variables, although achievers and philanthropists tend to enjoy them more than others.

7. Altruism elements are preferred by younger men, philanthropists, and socialisers.

8. Incentive elements are preferred by younger players, who score higher on neuroticism.

\section{Categories of Gameful Design Elements}

By looking at how the gameful design elements were classified in eight groups and three categories and comparing this model with prior literature on gaming motivations, we can understand how the users' experiences with gameful applications have remarkable differences in comparison with games. Artificially constructed challenges are at the heart of game design. Therefore, game-oriented models, such as Yee's gamer motivation profile [43], demonstrate players' preferences for different types of challenges, such as action, social, achievement, or creativity. Similarly, only socialization and immersion are present in both Hamari and Tuunanen's [20] proposed dimensions and 
our framework, and only socialization and exploration are present in both the BrainHex [27] and our framework, whereas the remaining motivations in those models refer to types of game challenges that are not common in gamification. Differently, the challenges faced by the user in a gameful application are usually real-world tasks, not artificially created tasks. Thus, gameful applications often aim to support the user in overcoming these natural challenges. Consequently, the groups of gameful design elements reflect different approaches to offer this support to users instead of creating different types of artificial challenges. In the following, we interpret the categories of design elements that emerged from our analysis with regard to this notion of natural compared to artificial challenges.

\section{Individual Motivations}

Both groups in this category include elements aimed at supporting the user at the individual level so they can successfully achieve their goals. Immersion enables users to have a more engaging experience, to feel that they are part of something bigger than themselves. On the other hand, progression helps users track their completed steps and plan the next ones towards achieving their goals. Thus, both design elements contribute to increasing the user's self-efficacy (i.e., their belief in their own abilities) within a gameful system.

\section{External Motivations}

These groups include elements aimed at providing external incentives for carrying out the activities that make up part of the gameful system. In this sense, incentive is the category that most clearly identifies different types of external incentives that are frequently used as sources of extrinsic motivation.

In contrast, risk and reward are harder to interpret as a group of gameful design elements. The elements in this group seem diverse, such as access to exclusive features, games of chance, and challenges. However, Caillois [11] has previously described this combination involving both games of skill and chance (agôn and alea in Caillois's play style classification). In this case, both types of game represent different means by which players can feel empowered to overcome the limitations that they face in real life. In games, every player has an equal chance of winning by either improving the skills required by the game or or via chance. Thus, winning is the feeling that users seek when facing challenges or lotteries. Even when the games are based on skill, there is still gambling involved, as winning depends as much on one's own skill as on the chance of facing an opponent which is less skilled. Hence, the thrill of the unexpected is also present, although in a different format than that of the games of chance, which depend solely on luck.

Finally, customization might also not seem like an obvious external motivation. However, the elements included in this group are means for the user to make the system work in their favour. Therefore, they empower users to modify the external factors that influence their ability to achieve their goals.

\section{Social Motivations}

The groups in this category include the elements that allow users to interact with others while carrying out their activities in the gameful system. Thus, socialization enables users to interact with each other, collaborate in carrying out their tasks, or compare themselves with others. Altruism allows users to feel they are part of something meaningful and make a contribution to a worthy cause. And finally, assistance allows users to receive aid from other users or from the system, thus, helping them alleviate any difficulty that they might experience in carrying out their tasks by themselves.

Comparison with prior Frameworks of Gamification Elements Our framework differs significantly from prior frameworks of gamification elements because it is the first approach to classify design elements based on user preferences. Robinson and Bellotti [37] suggested a model with six categories of gamification elements based on their role in the user experience. In comparison, only socialization and incentives are present in both their framework and ours, whereas the remaining categories are quite different. Exton and Murray [16] merely attributed to each element a potential to afford different types of motivation, without any organization in categories; therefore, our approach is remarkably different from theirs. Finally, Phillips et al. [34] and Rapp [36] focused exclusively on classifying rewards and incentives in games; thus, their works provide a more in-depth look into the design elements that are part of the incentives group in our framework. Since each one of these frameworks focused on different classification criteria, they are complementary and each one of them can contribute important information to the gameful design process. Remarkably, our framework is the first one to consider different user preferences in its construction, whereas the existing frameworks focus on different structural or motivational aspects without accounting for individual user differences.

\section{Usage of the Framework}

We have previously noted that most gameful design methods do not consider user preferences as part of their process. To address this issue, we suggest several possible usage scenarios for this framework. In a general approach, understanding the different groups of design elements and the overall characteristics of the users who are more likely to enjoy the elements from each group will allow gameful designers to create applications that can be potentially more attractive for the target user base. By understanding how different design elements appeal to different users, and which elements are similar in terms of user preferences, designers will be better equipped to employ a variety of elements instead of always relying on the same small subset of elements. Additionally, by knowing the characteristics of a product and of the population, marketing and customer relations can be better planned and directed.

Furthermore, this framework could be used to tailor the gameful experience for each particular user by adapting the system with the design elements that the user is more likely to enjoy. For this purpose, user preferences could be profiled automatically, by logging the frequency of user interaction with different activities. Alternatively, the user could be invited to answer a survey aimed at computing a preference score for each one of the eight groups. By knowing how the elements are grouped together, it is possible to assess an individual's preference for each one of the eight groups by asking them only about the elements that more strongly represent the group (i.e., the elements with the highest loading coefficients for each 


\begin{tabular}{c|c|c|c|c} 
& 1- Socialization & 2- Assistance & 3- Immersion & 4- Risk/Reward \\
\hline 1 & Social comparison & Glowing choice & Mystery box & Access \\
2 & Leaderboards & Beginner's luck & Easter eggs & Lotteries \\
3 & Social competition & Signposting & Theme & Boss battles \\
4 & Social networks & Anchor juxtaposition & Narrative/Story & Challenges \\
\hline$\alpha(3$ items $)$ & .875 & .691 & .624 & .475 \\
$\alpha(4$ items $)$ & .840 & .703 & .651 & .525
\end{tabular}

\begin{tabular}{|c|c|c|c|c|}
\hline & 5- Customization & 6- Progression & 7- Altruism & 8- Incentive \\
\hline 1 & Avatars & Levels/Progression & Knowledge sharing & Badges/Achievements \\
\hline 2 & Customization & Meaning/Purpose & Gifting & Certificates \\
\hline 3 & Points & Progress feedback & Innovation platforms & Collections \\
\hline 4 & Virtual economy & Learning & Development tools & Rewards/Prizes \\
\hline$\alpha$ (3 items) & .671 & .550 & .610 & .727 \\
\hline$\alpha$ (4 items) & .653 & .563 & .684 & .725 \\
\hline
\end{tabular}

Table 7. Top loading gameful design elements per group and internal reliability of subscales using only the top three or four elements per group.

component). Depending on the degree of accuracy desired, we suggest using three or four gameful design elements for each group to compute an overall individual preference score for the group. Table 7 demonstrates that the internal reliability remains above .60 for most groups even if only three or four elements are used. Therefore, by asking an individual about their preferences using a list of 24 (three per group) or 32 (four per group) gameful design elements, it is possible to estimate their preference for any one of the 49 studied elements with a reasonable degree of accuracy.

Moreover, the assessment of an individual's preference for elements of each group can also inform HCI research intended to study the mechanisms and effects of different elements. By understanding that different participants might have different dispositions to enjoy diverse gameful design elements, participants' scores in each group of design elements might be used as a control variable for the effects being studied.

\section{Limitations}

While our study design was valid and our results were significant, we had a few minor limitations. First, all measures were self-reported and, thus, subject to participants' level of understanding of the statements in the survey and their awareness of their own preferences toward diverse gameful design elements. Furthermore, the use of short scales is subject to acquiescence issues. This could be an issue because we used a short 10-items BFI scale due to the already considerable length of our survey. Nonetheless, the BFI-10 has been validated by several studies. Thus, we consider that our survey was adequate for the goals of our study, which were to explore possible factors that might influence user preferences without testing any particular hypothesis. Therefore, the findings from this study should represent an invitation for future research that could verify specific claims in focused studies.

Moreover, although our sample size was sufficient to perform the statistical analyses, our study was an exploratory pilot, aimed at constructing an initial conceptual framework of gameful design elements. Therefore, we intend to conduct additional studies with larger and more diverse samples to verify our findings and confirm the validity of our framework.
Finally, we did not observe participants' behaviour when interacting with gameful systems to verify if their scores in each one of the groups of gameful elements would predict their real behaviour. Hence, future studies will need to investigate the relationship between an individual's self-reported preferences and their actual behaviour in gameful systems.

\section{CONCLUSION}

The current study investigated user preferences for gameful design elements frequently employed in gamification. It is the first exploratory study to investigate design elements specifically used in gameful systems, instead of trying to generalize previous work in games user research to gamification. Specifically, this paper contributes to the HCI and gamification communities by presenting a novel model of eight groups of gameful design elements in three categories: individual motivations (immersion and progression); external motivations (risk/reward, customization, and incentives); and social motivations (socialization, altruism, and assistance).

Additionally, we have described the defining characteristics of each group and the gameful design elements that compose them. We also explained the typical characteristics of the users who are more likely to prefer each group. Finally, we have proposed different ways in which this framework can be used to inform gameful design. This can be achieved either by automatically profiling user preferences by observing their behaviour, or by explicitly asking users about their preferences toward a reduced set of elements and extrapolating their preferences for the remaining elements.

These findings extend our understanding of user preferences in gamification and will enable researchers and practitioners to design better tailored gameful systems in the future.

\section{ACKNOWLEDGMENTS}

This research was funded by the CNPq, Brazil, SSHRC (8952011-1014, IMMERSe), NSERC (RGPIN-418622-2012), CFI (35819), Mitacs (IT07255), and Agència de Gestió d'Ajuts Universitaris i de Recerca (Generalitat de Catalunya) through the Industrial Doctorate programme 2014-DI-006 in collaboration with Grupo ICA Barcelona. 


\section{REFERENCES}

1. Gabriel Barata, Sandra Gama, Joaquim Jorge, and Daniel Gonçalves. 2016. Studying student differentiation in gamified education: A long-term study. Computers in Human Behavior (2016). DOI :

http://dx.doi.org/10.1016/j.chb.2016.08.049

2. Gabriel Barata, Sandra Gama, Joaquim A.P. Jorge, and Daniel J.V. Gonçalves. 2014. Relating gaming habits with student performance in a gamified learning experience. In Proceedings of the first ACM SIGCHI annual symposium on Computer-human interaction in play - CHI PLAY' 14. ACM, New York, NY, USA, 17-25. DOI :

http://dx.doi.org/10.1145/2658537.2658692

3. Richard Bartle. 1996. Hearts, Clubs, Diamonds, Spades: Players who suit MUDs. Journal of MUD Research 1, 1 (1996).

4. Richard Bartle. 2005. Virtual Worlds: Why People Play. Massively Multiplayer Game Development 2, 1 (2005).

5. Chris Bateman, Rebecca Lowenhaupt, and Lennart E Nacke. 2011. Player Typology in Theory and Practice. Proceedings of DiGRA 2011 (2011).

6. Chris Bateman and Lennart E Nacke. 2010. The Neurobiology of Play. In Proceedings of Futureplay 2010. ACM, Vancouver, BC, Canada, 1-8. DOI : http://dx.doi.org/10.1145/1920778.1920780

7. Chris Mark. Bateman and Richard Boon. 2006. $21^{\text {st }}$ Century Game Design (Game Development Series). Charles River Media.

8. Blizzard Entertainment. 2004. World of Warcraft. Game [Windows/OS X]. (2004).

9. Marc Busch, Elke Mattheiss, Rita Orji, Peter Fröhlich, Michael Lankes, and Manfred Tscheligi. 2016. Player Type Models - Towards Empirical Validation. In Proceedings of the 2016 CHI Conference Extended Abstracts on Human Factors in Computing Systems. ACM. DOI : http://dx. doi .org/10.1145/2851581.2892399

10. Marc Busch, Elke Mattheiss, Rita Orji, Andrzej Marczewski, Wolfgang Hochleitner, Michael Lankes, Lennart E. Nacke, and Manfred Tscheligi. 2015. Personalization in Serious and Persuasive Games and Gamified Interactions. In Proceedings of the 2015 Annual Symposium on Computer-Human Interaction in Play CHI PLAY'15. ACM, 811-816. DOI : http://dx.doi.org/10.1145/2793107.2810260

11. Roger Caillois. 1961. Man, Play, and Games. University of Illinois Press.

12. Yu-kai Chou. 2017. Yu-kai Chou: Gamification \& Behavioral Design. (2017). http://yukaichou.com/

13. Sebastian Deterding. 2015. The Lens of Intrinsic Skill Atoms: A Method for Gameful Design.

Human-Computer Interaction 30, 3-4 (2015), 294-335. DOI : http://dx.doi .org/10.1080/07370024.2014.993471
14. Sebastian Deterding, Dan Dixon, Rilla Khaled, and Lennart E Nacke. 2011. From Game Design Elements to Gamefulness: Defining "Gamification". In Proceedings of the $15^{\text {th }}$ International Academic MindTrek Conference. ACM, ACM, Tampere, Finland, 9-15. DOI : http://dx.doi.org/10.1145/2181037.2181040

15. Enterprise Gamification. 2017. Gamification Design Elements. (2017). http://enterprise-gamification.com/ mediawiki/index .php?title=Gamification_Design_Elements

16. Geraldine Exton and Liam Murray. 2014. Motivation: A Proposed Taxonomy using Gamification. (2014). http://hdl.handle.net/10344/4279

17. Lauren S. Ferro, Steffen P. Walz, and Stefan Greuter. 2013. Towards personalised, gamified systems: an investigation into game design, personality and player typologies. In Proceedings of the $9^{\text {th }}$ Australasian Conference on Interactive Entertainment: Matters of Life and Death - IE '13. 1-6. DOI :

http://dx.doi.org/10.1145/2513002.2513024

18. Andy Field. 2009. Discovering Statistics Using SPSS ( $3^{\text {rd }}$ ed.). Sage Publications, London, UK.

19. Lewis R Goldberg. 1993. The structure of phenotypic personality traits. American Psychologist 48, 1 (1993), 26. DOI : http://dx.doi .org/10.1037/0003-066X .48.1.26

20. Juho Hamari and Janne Tuunanen. 2014. Player types: A meta-synthesis. Transactions of the Digital Games Research 1, 2 (2014). http://todigra.org/index.php/todigra/article/view/13

21. Yuan Jia, Bin Xu, Yamini Karanam, and Stephen Voida. 2016. Personality-targeted Gamification: A Survey Study on Personality Traits and Motivational Affordances. In Proceedings of the $34^{\text {th }}$ Annual ACM Conference on Human Factors in Computing Systems - CHI '16. DOI : http://dx.doi.org/10.1145/2858036.2858515

22. Andrzej Marczewski. 2015. Even Ninja Monkeys Like to Play: Gamification, Game Thinking \& Motivational Design. CreateSpace Independent Publishing Platform.

23. Andrzej Marczewski. 2017. User Types in Gamification. SlideShare. (Feb 2017). https://www.slideshare.net/ daverage/gamification-player-types-talk-2017

24. Alberto Mora, Daniel Riera, Carina González, and Joan Arnedo-Moreno. 2017. Gamification: a systematic review of design frameworks. Journal of Computing in Higher Education (23 May 2017). DOI :

http://dx.doi.org/10.1007/s12528-017-9150-4

25. Benedikt Morschheuser, Karl Werder, Juho Hamari, and Julian Abe. 2017. How to gamify? A method for designing gamification. In Proceedings of the $50^{\text {th }}$ Annual Hawaii International Conference on System Sciences (HICSS). IEEE, Hawaii, USA. DOI : http://dx.doi.org/10125/41308

26. Isabel Briggs Myers. 1962. The Myers-Briggs Type Indicator. Consulting Psychologists Press, Palo Alto, CA. 
27. Lennart E Nacke, Chris Bateman, and Regan L Mandryk. 2014. BrainHex: A Neurobiological Gamer Typology Survey. Entertainment Computing 5, 1 (2014), 55-62. DOI : http://dx. doi .org/10.1016/j . entcom. 2013.06.002

28. Scott Nicholson. 2014. A RECIPE for Meaningful Gamification. In Gamification in Education and Business, Torsten Reiners and Lincoln C. Wood (Eds.). Springer, 1-20. DOI : http://dx.doi .org/10.1007/978-3-319-10208-5

29. Brian P O'Connor. 2000. SPSS and SAS programs for determining the number of components using parallel analysis and Velicer's MAP test. Behavior Research Methods, Instruments, \& Computers 32, 3 (2000), 396-402. DOI : http://dx. doi .org/10.3758/BF03200807

30. Rita Orji, Regan L. Mandryk, Julita Vassileva, and Kathrin M. Gerling. 2013. Tailoring persuasive health games to gamer type. In Proceedings of the SIGCHI Conference on Human Factors in Computing Systems CHI'13. 2467-2476. D0I :

http://dx.doi.org/10.1145/2470654.2481341

31. Rita Orji, Lennart E. Nacke, and Chrysanne DiMarco. 2017. Towards Personality-driven Persuasive Health Games and Gamified Systems. In Proceedings of the SIGCHI Conference on Human Factors in Computing Systems. ACM. DOI :

http://dx.doi.org/10.1145/3025453.3025577

32. Rita Orji, Julita Vassileva, and Regan L. Mandryk. 2014. Modeling the efficacy of persuasive strategies for different gamer types in serious games for health. User Modeling and User-Adapted Interaction 24, 5 (2014), 453-498. DOI :

http://dx.doi.org/10.1007/s11257-014-9149-8

33. Nicole Peever, Daniel Johnson, and John Gardner. 2012. Personality \& Video Game Genre Preferences. In Proceedings of The $8^{\text {th }}$ Australasian Conference on Interactive Entertainment: Playing the System. ACM, 20. DOI : http://dx.doi.org/10.1145/2336727.2336747

34. Cody Phillips, Daniel Johnson, Peta Wyeth, Leanne Hides, and Madison Klarkowski. 2015. Redefining Videogame Reward Types. In Proceedings of the Annual Meeting of the Australian Special Interest Group for Computer Human Interaction. ACM, 83-91. D0I : http://dx.doi.org/10.1145/2838739.2838782

35. Beatrice Rammstedt and Oliver P. John. 2007. Measuring personality in one minute or less: A 10-item short version of the Big Five Inventory in English and German. Journal of Research in Personality 41, 1 (2007), 203-212. DOI: http://dx.doi.org/10.1016/j.jrp.2006.02.001
36. Amon Rapp. 2017. From Games to Gamification: A Classification of Rewards in World of Warcraft for the Design of Gamified Systems. Simulation \& Gaming 48, 3 (2017), 381-401. DOI : http://dx.doi.org/10.1177/1046878117697147

37. David Robinson and Victoria Bellotti. 2013. A preliminary taxonomy of gamification elements for varying anticipated commitment. In Workshop on Designing Gamification: Creating Gameful and Playful Experiences.

38. Richard M. Ryan and Edward L. Deci. 2000. Self-determination theory and the facilitation of intrinsic motivation, social development, and well-being. The American Psychologist 55, 1 (2000), 68-78. DOI: http://dx.doi.org/10.1037/0003-066X.55.1.68

39. Richard M. Ryan, C. Scott Rigby, and Andrew Przybylski. 2006. The motivational pull of video games: A self-determination theory approach. Motivation and Emotion 30, 4 (2006), 347-363. DOI : http://dx.doi.org/10.1007/s11031-006-9051-8

40. Gustavo F. Tondello, Rina R. Wehbe, Lisa Diamond, Marc Busch, Andrzej Marczewski, and Lennart E. Nacke. 2016. The Gamification User Types Hexad Scale. In Proceedings of the 2016 Annual Symposium on Computer-Human Interaction in Play - CHI PLAY' 16. ACM, Austin, TX, USA. DOI : http://dx.doi.org/10.1145/2967934.2968082

41. Kevin Werbach and Dan Hunter. 2015. The Gamification Toolkit: Dynamics, Mechanics, and Components for the Win. Wharton Digital Press, Philadelphia, PA.

42. Nick Yee. 2006. Motivations for Play in Online Games. CyberPsychology \& Behavior 9, 6 (dec 2006), 772-775. DOI : http://dx.doi.org/10.1089/cpb.2006.9.772

43. Nick Yee. 2015. Gamer Motivation Model Overview and Descriptions. Quantic Foundry. (Dec 2015). http://quanticfoundry.com/2015/12/15/handy-reference/

44. Nick Yee, Nicolas Ducheneaut, and Les Nelson. 2012. Online gaming motivations scale: development and validation. In Proceedings of the 2012 ACM annual conference on Human Factors in Computing Systems CHI' 12. ACM, New York, New York, USA, 2803. DOI : http://dx.doi.org/10.1145/2207676.2208681

45. Gabe Zichermann and Christopher Cunningham. 2011. Gamification by Design: Implementing game mechanics in web and mobile apps. O'Reilly. 